\title{
POLÍTICA NACIONAL SOBRE O ÁLCOOL - LEI SECA: UMA AVALIAÇÃO NO CONTEXTO DA POLÍCIA MILITAR
}

\author{
T. M. M. COSTA' ${ }^{1}$, R. M. ARAÚJO ${ }^{2}$, L. C.I B. GUERRA ${ }^{3}$ \\ Universidade Federal do Rio Grande do Norte \\ richardmaraujo@uol.com.br²
}

Submetido 28/03/2019 - Aceito 01/08/2019

DOI: $10.15628 /$ holos. 2020.8457

\section{RESUMO}

Este paper objetivou avaliar a política pública da Lei Seca através da percepção dos oficiais da Polícia Militar de um estado da Federação, levando em consideração critérios sociais, legais e financeiros intrínsecos a essa política. Metodologicamente, fora disponibilizado um questionário por meio de aplicativo de troca de mensagens instantâneas para smartphones, grupo formado apenas por oficiais, dos mais variados postos. Foi realizada uma pesquisa descritiva com abordagem quantitativa, dando enfoque à representatividade numérica por meio de porcentagens. Os principais resultados mostram o alinhamento das opiniões dos colaboradores da pesquisa, com os objetivos que a Lei Seca busca alcançar, traduzindo em melhorias para a sociedade, porém, com a necessidade de envolvimento de mais atores na parceria da condução da política. Concluise que a população sabe dos limites impostos pela lei, que ainda há consumo de bebidas alcoólicas por parte dos condutores de veículos, os quais conhecem as pesadas punições impostas aos transgressores e que, mesmo com a diminuição de acidentes e a mudança de comportamento com a relação álcool-volante, as iniciativas dentro da Lei Seca devem permanecer e progredir.

Palavras-chave: Avaliação de política pública, Lei Seca, Polícia Militar.

\section{BRAZILIAN NATIONAL POLICY ON ALCOHOL - "DRIVING UNDER THE INFLUENCE (DUI) LAW: AN EVALUATION IN THE POLICE CONTEXT."}

\begin{abstract}
This paper aimed to evaluate the public policy of dry law through the perception of military police officers of a State of the Federation, taking into account social, legal and financial criteria intrinsic to this policy. Methodologically, a questionnaire had been made available through an instant messaging application for smartphones, a group formed by only officers, from the most varied stations. A descriptive research with a quantitative approach was carried out, giving a focus to the numerical representativeness by means of percentages. The main results show the alignment of the opinions of the research
\end{abstract}

collaborators with the objectives that the dry law seeks to achieve, translating into improvements for society, but with the need to involve more actors in the partnership of conducting the policy. It is concluded that the population knows the limits imposed by the law, there is still consumption of alcoholic beverages by drivers of vehicles, who know the heavy penalties imposed on transgressors and that, even with the reduction of accidents and behavior change with the alcohol-steering relationship, initiatives within the dry law must remain and progress.

Keywords: Political evaluation, Dry-Law, Military Police. 


\section{INTRODUÇÃO}

O consumo excessivo de bebidas alcoólicas é de longa data, conhecido causador de problemas de saúde na população brasileira (Malta et. al., 2014), além de aumento das causas externas de violência, que podem ser resumidas em homicídios, suicídios e acidentes em geral. Visando colocar o governo em ação, a fim de gerar resultados e efeitos com a solução de problemas, têm sido criadas políticas públicas de visão holística, gerando mudanças na realidade social, como a Política Nacional Sobre o Álcool, conhecida popularmente como Lei Seca.

Esta vem proporcionar bases que norteiem as ações e metodologias de enfrentamento desse problema de abrangência nacional. A Nova Lei Seca surge com a necessidade de evolução e potencialização dos efeitos pretendidos pelo novo Código de Trânsito, instituído pela Lei 9.503/97.

A Pesquisa Nacional de Saúde de 2015, desenvolvida pelo Ministério da Saúde e Instituto Brasileiro de Geografia e Estatística, que coletou dados de julho de 2013 a fevereiro de 2014, atestou que, mesmo após 16 anos de vigência do novo Código, 24,3\% dos motoristas afirmam assumir a direção de veículos automotores após o consumo de bebidas alcoólicas. Esse dado reforça a urgência em desenvolver mecanismos mais eficazes ao combate de práticas dessa natureza. Somente no ano de 2014, acidentes de trânsito de maneira geral foram responsáveis por 172.790 internações. (IBGE, 2015).

As blitz da Lei Seca - aliada a outras iniciativas conjuntas, como a rápida aplicação de medidas punitivas, campanhas educativas, capacitação de profissionais e agentes multiplicadores de assuntos relacionados ao tema e etc. - têm o intuito de coibir, através de punições mais rígidas, e gerar uma nova cultura de sobriedade no trânsito. A Polícia Militar, como órgão responsável pela polícia ostensiva e a preservação da ordem pública, assim como a incolumidade de pessoas e do patrimônio, tem papel fundamental na implementação e execução dessa política tão importante para a sociedade.

A Lei Seca foi criada pela Lei 11.705 , em julho de 2008 , e alterou dispositivos da Lei no 9.503/97, que instituiu o Código de Trânsito Brasileiro, "com a finalidade de estabelecer alcoolemia 0 (zero) e de impor penalidades mais severas para o condutor que dirigir sob a influência do álcool". A nova legislação estende as penalidades para o condutor que apresentar "qualquer concentração de álcool por litro de sangue", ou seja, quanto maior a presença do entorpecente na corrente sanguínea fica mais evidente o descumprimento à norma".

Em 2012, houve novas mudanças trazidas pela Lei no 12.760: aumento de mais de $100 \%$ da multa, supressão da exigência de confirmação de seis ou mais decigramas de álcool por litro de sangue para caracterização do crime de embriaguez ao volante, abrindo a possibilidade de outras provas além do teste do etilômetro.

Em 2016, nova mudança: a multa para o motorista dirigindo sob o efeito de álcool ou que se recuse a fazer o teste do etilômetro subiu para $\mathrm{R} \$ 2.934,70$, com suspensão da carteira de motorista por 12 meses. 
A Lei Seca está prestes a completar 10 anos desde a sua primeira versão, e nesse período, dados do Ministério da Saúde apontam que em 2007 o Brasil houve 20,3 mortes no trânsito por cada 100 mil habitantes; 20,2 em 2008 e 19,6\% em 2009; os números voltaram a subir nos anos seguintes (22,5 em 2010, 22,5 em 2011 e 23,1 em 2012), mas voltaram a cair desde as mudanças na legislação, com 20,1 em 2013 e em 2012: (Ibge, 2015). A saliência dessa política pública justifica a necessidade do desenvolvimento de mais pesquisas avaliativas em âmbito acadêmico.

Sistematicamente, a Avaliação de Politica Pública não é de uma área de pesquisa que avança no Brasil, como lembraram Bechelaine \& Ckagnazaroff (2014): há uma escassez de estudos teóricos que versem sobre o tema. Por outro lado, nessas pesquisas avaliativas, como lembra Neirotti (2012), as evidências resultantes dessas avaliações devem sobrepor ao Estado e à Sociedade a qualidade da ação governamental e o alcance da intervenção social estabelecida, assim como gerar uma reflexão sobre a real eficiência com a busca da solução do problema constatado quando da formação da respectiva ação, gerando maior transparência política e porque não dizer a responsabilização dos atores.

Com isso, o presente artigo visa avaliar a Política Nacional sobre o Álcool - Lei Seca através da percepção dos Oficiais da Polícia Militar de um estado da Federação sobre sua abrangência nos aspectos legal, social e financeiro.

\section{REFERENCIAL TEÓRICO}

\subsection{Políticas Públicas}

Não há conceito único de política pública, tampouco sobre a melhor forma de defini-la, como afirma Souza (2006). A autora continua sua obra expondo que existem vários teóricos e pesquisadores sobre o tema, consequentemente, são inúmeras suas definições. Ela ainda aborda o papel holístico do campo de políticas públicas, enfatizando seu terreno fértil para a multidisciplinaridade, teorias e modelos analíticos. Trevisan \& Bellen (2008) somam a ideia de que é da essência da área a multidisciplinaridade, razão pela qual estudos setoriais transitam em diversas áreas do conhecimento.

Paviani (2009) assinala que a cidadania tem apresentado demandas e se manifestado em diversos campos, sobretudo quanto à atuação governamental, lacunosa em setores importantes, como saúde pública, desenvolvimento educacional, transportes coletivos, políticas habitacionais. Teixeira (2002) trata que as políticas têm o intuito de ampliar e efetivar direitos de cidadania, cujo embrião surge nas lutas sociais e que passam a ser reconhecidos pelo governo como instituição. Como objetivo das políticas públicas, temos a seguinte explanação:

As políticas públicas visam responder a demandas, principalmente dos setores marginalizados da sociedade, considerados como vulneráveis. Essas demandas são interpretadas por aqueles que ocupam o poder, mas influenciadas por uma agenda que se cria na sociedade civil através da pressão e mobilização social. (Teixeira, 2002, p.3). 
Com o aprofundamento da crise do welfare state, com as convulsões econômicas, sociais e políticas enfrentadas, principalmente a partir do final da década de 1970, junto com o movimento da nova administração pública, o Estado é fortemente questionado tanto em suas funções quanto na real eficácia de suas ações interventoras na realidade social (Trevisa \& Bellen, 2008. No momento de transição do período de governo militar para o democrático, as mudanças na sociedade eram latentes e levaram o Brasil a experimentar um aumento nas ofertas de políticas públicas voltadas ao social. Nesse período, as desigualdades na sociedade aumentaram devido a crises econômicas, fiscais e de reformas, e travou-se uma luta para inserir as demandas nos debates da agenda de desenvolvimento (Paes-Souza, 2014; Costa \& Castanhar,2008).

Com o intuito de apresentar uma visão mais ampla do complexo sentido do que é política pública, corroborando com tudo o que fora escrito nesse capítulo, pode-se citar o seguinte trecho:

As políticas públicas serão aqui entendidas como o conjunto de políticas, programas e ações do Estado, diretamente ou por meio de delegação, com objetivo de enfrentar desafios e aproveitar oportunidades de interesse coletivo. Tais políticas, programas e ações concretizam-se na oferta de bens e serviços que atendam as demandas resultantes das disputas políticas acerca do que é ou deveria ser de interesse público. O conceito de política pública pressupõe, portanto, o reconhecimento de que há uma área ou domínio da vida que não é privada ou somente individual. (Castro \& Oliveira, 2014, p.22-23).

A edificação da essência da cidadania e da inclusão social, seja tratada de forma singular ou coletiva, implica ações de setores múltiplos, desenvolvidas com integralidade das esferas de governos existentes unidos à população. Isso se justifica pelo entendimento de que pois a intersetorialidade ganha corpo dentro das relações articuladas pelo governo com a sociedade organizada, propiciando terreno fértil à cidadania no momento em que é ampliado o caráter público das ações conjuntas entre esses diversos atores (Cns, 2004).

Os pesquisadores Castro \& Oliveira (2014) ainda explicam que, dentro de qualquer escala, as políticas públicas tendem a referenciar problemas eminentemente públicos, em oposição aos problemas privados. Dentro das sociedades atuais, é dever do Estado prover políticas públicas que atendam aos anseios da sociedade. São de suma importância ações de planejamento e permanente interação entre os órgãos do governo e a sociedade para que as funções do Estado sejam exercidas com legitimidade. Além desse exercício, seria uma das obrigações buscar um meio com o intuito de serem pactuados objetivos e metas que orientem a formulação e a implementação das políticas públicas.

\subsection{Política Nacional sobre o Álcool: Uma Evolução Necessária}

O fenômeno do uso abusivo de substâncias psicoativas, na sociedade atual, tem se constituído problemática acentuadamente complexa e, embora as transformações históricoculturais e as inovações científico-tecnológicas sejam marcantes, nos últimos anos, as concepções e modelos de abordagem prática de tal fenômeno não têm avançado significativamente e requerem estudos e reflexões, como apontam Souza e Kantorski (2007). 
Além dessa perspectiva, as pesquisadoras acima são enfáticas ao escreverem que:

As drogas, lícitas e ilícitas, devido às consequências de seu uso abusivo, à influência que exercem nos fatores externos (violência, agressão, mortes problemas familiares, perdas afetivas), quer pelo consumo, quer pelo tráfico, além de seus reflexos na saúde pública brasileira (decorrente de internações, atendimentos de emergência etc.) se constituem, de fato, em problema social no Brasil (Souza \& Kantorsky, 2007 p.2).

Até o final do século XX, mais precisamente até o ano de 1998, não existia no Brasil, alguma política ou iniciativa estatal sobre o tema da redução da demanda e da oferta de drogas, como informa o Observatório Brasileiro de Informações sobre Drogas (Odib, 2017). Após a realização da XX Assembleia Geral Especial das Nações Unidas, na qual se tratou dos princípios diretivos a fim de redução da demanda de drogas. O Brasil adere ao movimento e toma as medidas de transformar o Conselho Federal de entorpecentes (CONFEN) em Conselho Nacional Antidrogas (SENAD).

Em 2002, foi criado, através do Decreto Presidencial no 4.345, de 26 de Agosto, a Política Nacional Antidrogas (PNAD). Nos primeiros anos de existência dessa política, o tema manteve-se em pauta, tendo necessidade de aprofundamento. Dessa forma, foi necessário rever alguns fundamentos da PNAD, levando em conta as transformações sociais, políticas e econômicas vivenciadas no mundo (Brasil, 2011).

Essa nova fase da política relativa às drogas teve como premissa, a grande interação entre governo e sociedade. A participação da população na PNAD visava proporcionar o caráter democrático e participativo que toda política pública deve ter em sua constituição. Muito mais que a participação da comunidade científica e governo, a sociedade como agente participativo era fator determinante para o alcance do sucesso (Brasil, 2011).

Sobre o processo de participação social nas políticas, a formulação e o controle de políticas públicas criam a possibilidade e, simultaneamente, fundamentam as engrenagens para a gestão participativa, a qual tem o intuito de proporcionar a legitimidade de ações governamentais, tornando sustentáveis seus programas, projetos e políticas apresentadas (12a Cns, 2004).

Em 2005, a política realinhada passou-se a chamar Política Nacional Sobre Drogas, através da Resolução no 3/GSIPR/CH/CONAD, de 27 de outubro. A nova política veio trazer claramente os pressupostos, objetivos, diretrizes e as diversas estratégias para consolidar os esforços, no intuito de implementar a redução das demandas, no que diz respeito às drogas, tendo seu escopo baseado em cinco vertentes - a prevenção, tratamento, recuperação e reinserção social, redução dos danos sociais e à saúde, redução da oferta e estudos, pesquisas e avaliações (Souza \& Kantorsky, 2007).

No ano de 2006, foi aprovada a Lei no 11.343, de 23 de agosto, a qual trata da instituição do Sistema Nacional de Políticas Sobre Drogas, cuja finalidade é traçar toda uma metodologia de ações, como articulação, integração, organização e coordenação de atividades voltadas à prevenção, tratamento e reinserção social dos usuários e dependentes de drogas, assim como a repressão ao tráfico. Também se destacam a diferenciação de usuários, dependentes e traficantes, em que os dois primeiros não mais serão penalizados com penas privativas de liberdade, restando a esses, medidas socioeducativas (Duarte \& Brando, 2011). 
A sociedade contemporânea é tomada por riscos e situações complexas. Com a busca atual pela redução dos danos ou riscos sociais, políticas como a do desarmamento, distribuição de preservativos, antitabagismo, além de outras, fazem parte de medidas de saúde pública, visando um melhor bem-estar da população, apesar de, muitas vezes, mostrar-se uma realidade contraditória. Numa sociedade ávida por consumo, o ritmo de vida leva o cidadão a situações de risco na gestão da vida, induzindo, dessa forma, ao provimento de meios que dirimam os danos (Adorno, 2008).

\subsection{Avaliação de Políticas Públicas}

Segundo Maia (2017, p. 81), com a consolidação do campo de estudo das políticas públicas, tornou-se imperativo o desenvolvimento de um processo de avaliação dessas políticas, sendo a avaliação um "subcampo, um momento necessário nos estudos de políticas públicas".

A avaliação é um dos estágios do ciclo de políticas públicas, não havendo maiores divergências sobre conceitos de avaliação, vários investigadores trazem intervenções sobre esse entendimento (Ramos \& Schabbacch, 2012).

Thoenig (2000) trata essa ação como um meio de aperfeiçoar a capacidade de aprender como conduzir mudanças bem-sucedidas e definir resultados alcançáveis nos campos da eficiência e eficácia públicas. $\mathrm{O}$ autor ainda mostra a prática avaliativa como uma atividade comprometida na produção e análise de informações relevantes e pertinentes a respeito da relação entre os atos públicos, seus resultados e impactos.

Para Tinoco, Souza \& Oliveira (2011), a incapacidade das políticas cumprirem os resultados esperados têm sido observada reiteradamente na literatura especializada, tornando ainda mais premente e necessária a atividade avaliativa.

A avaliação das políticas públicas tem como principal objetivo embasar com dados confiáveis os tomadores de decisão. Ala-Harja \& Helgason (2000) corroboram esse entendimento com a ideia de que a finalidade avaliativa garante melhores informações aos governantes, podendo fundamentar suas decisões e levando melhoria contínua na prestação de contas sobre as políticas e os programas públicos.

Maia (2017, p. 81) compreende o processo de avaliação como "apreciar os efeitos atribuíveis a uma intervenção do governo em um campo específico da vida social". Dulci (2010) destaca como principal contribuição para o aperfeiçoamento das políticas públicas, visto que é através desse deste processo que os gestores podem justificar a alocação de recursos e pessoas para a execução das políticas. Para os autores, uma das metas principais da atividade avaliativa é descrita como a melhoria da tomada de decisão, pois auxilia os formuladores das políticas no entendimento do trabalho realizado e de sua condução.

Outra meta é o auxílio na alocação de recursos, evitando desperdícios financeiros, melhor distribuindo os recursos e para fazer bom uso dos fundos disponíveis, gerando um nível adequado de gasto nas ações prioritárias. Por fim, o aumento da responsabilidade trazido pela maior autonomia administrativa é oportunizada pelas reformas gerenciais. 
A respeito dos tipos de avaliação existentes, Schoenefeld \& Jordan (2017) destacam inicialmente - os modelos formais e informais: as formais, costumeiramente, são desenvolvidas por atores estatais, que costumam ter maior conhecimento dos processos políticos e circunstâncias sobre as quais uma determinada política emergiu, fazendo com que a avaliação seja mais sintonizada com as variáveis relacionadas. Weiss (1993), entretanto, afirma que, em avaliações, os atores de avaliação governamental podem ser menos críticos de uma determinada política e seus resultados do que o conhecimento gerado por atores não estatais, passando a evitar-se um olhar muito crítico.

As avaliações informais, realizadas por atores não-estatais, tendem a adotar uma visão mais crítica, uma vez que os avaliadores, ou seus financiadores, podem avaliar a política pública justamente para expor suas falhas. Mickwitz (2013) ainda destaca que esse tipo de avaliação pode utilizar uma maior variedade de critérios. No entanto, Jacob, Speer \& Furubo (2015), destacam que os atores informais também podem ter interesses, muitas vezes, alinhados com os de seus financiadores, podendo levar ao "viés de confirmação".

Como medida de desempenho dos programas advindos das políticas, Costa \& Castanhar (2003) trabalham alguns critérios como a eficiência, eficácia, impacto ou efetividade e sustentabilidade, além de outros como: análise custo-efetividade, satisfação do beneficiário e equidade, quando o grau em que os benefícios de um programa estão sendo distribuídos de maneira justa e compatível com as necessidades do usuário. Costa \& Castanhar (2003) continuam o raciocínio mostrando que a aplicação desses critérios requer formas específicas de operacionalização, já que constituem medidas indiretas, ou seja, que devem ser calculadas a partir da identificação e quantificação dos resultados obtidos. Em geral, denomina-se essa outra categoria de medidas de indicadores, relacionando diversos tipos, dependendo da área e da finalidade da avaliação.

Por fim, visando avaliar o desempenho de um programa, Costa \& Castanhar (2003) definem padrões de referência com o intuito de julgar esse desempenho. Eles elencam os seguintes padrões: Absolutos, Históricos, Normativos, Teóricos e negociados ou de Compromisso.

Athey \& Imbens (2017) destacam o importante papel que a econometria possui, atualmente, nos estudos de avaliação de políticas públicas, mesmo reconhecendo que estabelecer inferências sobre o efeito causal de uma política pública a partir de dados observacionais é bastante desafiador.

Um dos desafios do processo de avaliação de políticas públicas apontados por Maia (2017, p. 90) é que esse "exige profundidade", uma vez que "permite a aplicação do conhecimento do programa e sua utilização deve ter sentido social". A autora ainda aponta a compreensão do contexto em que a política ocorre, bem como a correta formatação de uma metodologia que estabeleça critérios e indicadores adequados ao correto julgamento da política pública em questão, sendo importante a utilização de equipes multidisciplinares. 


\section{METODOLOGIA}

Como objetivo, no presente artigo, foi realizada uma pesquisa descritiva, pois esta tem como finalidade a descrição de características da população investigada, no caso, a percepção dos Oficiais da Polícia Militar sobre os efeitos da Lei Seca.

A fim de verificar o entendimento da efetividade da Lei Seca por parte dos Oficiais da Polícia Militar, foi feita uma pesquisa documental do Estatuto da Polícia Militar, cujo texto fora regulamentado através da Lei Estadual, a qual conceitua a estrutura funcional dos quadros de oficiais, sua quantidade atual e a razão pela qual esse grupo específico de servidores foi selecionado, a fim de embasar a presente pesquisa.

A abordagem foi quantitativa, pois foi feita análise de dados brutos advindos do preenchimento dos questionários, recorrendo e dando enfoque à representatividade numérica. Esse tipo de abordagem tem suas raízes no pensamento positivista lógico, tendendo levar a um raciocínio dedutivo, as regras da lógica e atributos mensuráveis da experiência humana (Silveira \& Córdova, 2009).

Os Oficiais da Polícia Militar - em estudo - são divididos em graus hierárquicos, compreendendo 03 (três) categorias - os oficiais superiores, oficiais intermediários e oficiais subalternos. Os superiores compreendem os postos de Major, Tenente-Coronel e Coronel, sendo estes, de nível estratégico dentro da instituição. Os oficiais intermediários são aqueles que ocupam o posto de Capitão, com funções em nível tático. Por fim, ocupando o nível operacional de comando, existem os Primeiros-Tenentes e os Segundos-Tenentes. Aos Oficiais, sendo preparados ao longo da carreira militar, cabem os cargos de chefia e Comando, que são a soma de autoridade, deveres e responsabilidade, além da direção das Organizações Policiais-Militares.

A Polícia Militar, à qual pertencem Oficiais contribuintes desta pesquisa, é uma organização integrante do aparelho de segurança pública, juntamente aos demais órgãos inseridos na Carta Magna de 1988, nesta República. Fora designada responsável pela polícia ostensiva e pela preservação da ordem pública, assim como a incolumidade das pessoas e do patrimônio. Sua estrutura, segundo o portal digital da corporação militar estadual, está alicerçada em órgãos de apoio, atendendo à atividade-meio, e órgãos de execução, constituídos por unidades operacionais, atuando na atividade-fim na capital, região metropolitana e interior do estado.

A Instituição policial-militar englobada neste estudo é composta por 03 (três) comandos operacionais, sendo eles o Comando de Policiamento Metropolitano (CPM), Comando de Policiamento do Interior (CPI) e o Comando de Policiamento Rodoviário Estadual (CPRE), responsável pela fiscalização e patrulhamento nas rodovias estaduais que cortam o estado. Existem, também, órgãos de apoio, os quais exercem, prioritariamente, atividades de cunho administrativo.

Foram aplicados questionários online, fechados, contendo 26 (vinte e seis) questões, entre afirmativas e perguntas de múltipla escolha. O instrumento de obtenção dos dados foi confeccionado através da plataforma digital Google Formulários. Teve seu período de aplicação compreendido entre os dias 17/04/2017 e 27/04 do mesmo ano, portanto, 10 (dez) dias recebendo 
as respostas. O questionário foi disponibilizado em meio digital, através do aplicativo de trocas de mensagens instantâneas para telefones móveis, no qual o pesquisador reiterava junto aos sujeitos que participassem da pesquisa de campo.

O universo da pesquisa foram os Oficiais da Polícia Militar, em todos os postos existentes, com um total de 155 integrantes. Foram obtidas 67 respostas durante os 10 dias em que o questionário permaneceu aberto, recebendo os dados enviados pelos questionados. Com as respostas disponíveis, passou-se a compilar e analisar os dados obtidos. Dessa forma, obteve-se uma amostra aproximada de 43\%, caracterizando uma amostragem por acessibilidade, a qual, segundo Gil (2008), é o menos rigoroso de todos os tipos amostrais, destituída de qualquer rigor estatístico.

Foram coletados dados socioeconômicos e demográficos (questões 1 até 7); comportamento de pessoas com o cotidiano da Lei Seca (questões 8, 9, 10 e 19); entendimento do entrevistado sobre os efeitos gerais da Lei Seca (questões 11 até 26). As questões do primeiro bloco (questões de 1 até 10, mais a questão 19) eram de múltipla escolha e no segundo bloco, composto pelas demais questões, exceto a questão 19, tratou-se de assertivas com graus de concordância das variáveis de "Discordo Totalmente" a "Concordo Totalmente", em formato de escala tipo "Likert" de 5 (cinco) pontos.

Os dados apresentados foram tratados a partir da estatística descritiva por meio de porcentagens, com a finalidade de estabelecer comparações relativas. Inicialmente, os dados foram disponibilizados na plataforma digital Google Forms.

Posteriormente, a fim de explicitar e compilar os dados desta pesquisa, decidiu-se por implantá-los sob forma de tabelas, pois estas - segundo as normas de apresentação tabular da Fundação Instituto Brasileiro de Geografia e Estatística (Ibge, 1993) - são formas não discursivas de apresentar informações, das quais o dado numérico se destaca como informação central. Elas fornecem uma ideia mais precisa e tornam possível uma análise mais detalhada dos dados inseridos.

Foi feita ainda uma análise dos documentos oficiais da Polícia Militar, como o estatuto.

\section{ANÁLISE E DISCUSSÃO DOS DADOS}

Após o recebimento dos questionários, puderam-se verificar, através das tabelas abaixo, as variáveis da pesquisa. A partir da tabela (Tab.1) apresenta-se a composição sociodemográfica dos oficiais da PM investigados:

Tabela 1. Dados Socioeconômicos e Demográficos

\begin{tabular}{|c|c|c|c|c|c|c|}
\hline $\begin{array}{c}1 . \\
\text { Sexo }\end{array}$ & $\begin{array}{c}2 . \\
\text { Estado Civil }\end{array}$ & $\begin{array}{c}3 . \\
\text { Qtde. } \\
\text { Filhos }\end{array}$ & $\begin{array}{c}4 . \\
\text { Grau de } \\
\text { Escolaridade }\end{array}$ & $\begin{array}{l}5 . \\
\text { Local de } \\
\text { residência }\end{array}$ & $\begin{array}{c}6 . \\
\text { Posto/ } \\
\text { Patente }\end{array}$ & $\begin{array}{c}7 . \\
\text { Comando } \\
\text { Pertencente }\end{array}$ \\
\hline \multirow{2}{*}{$\begin{array}{l}\text { Masculino } \\
\quad 97 \%\end{array}$} & $\begin{array}{c}\text { Casado } \\
70,1 \%\end{array}$ & \multirow{2}{*}{$\begin{array}{l}\operatorname{Sim} \\
67,2 \%\end{array}$} & $\begin{array}{c}\text { Superior } \\
\text { Incompleto } \\
2,3 \%\end{array}$ & $\begin{array}{l}\text { Capital } \\
55,2 \%\end{array}$ & $\begin{array}{c}\text { Of. Superior } \\
20,9 \%\end{array}$ & $\begin{array}{c}\text { CPI } \\
20,9 \%\end{array}$ \\
\hline & $\begin{array}{c}\text { Solteiro } \\
17,9 \%\end{array}$ & & $\begin{array}{c}\text { Superior Completo } \\
62,7 \%\end{array}$ & $\begin{array}{c}\text { Região } \\
\text { Metropolitana }\end{array}$ & $\begin{array}{c}\text { Of. } \\
\text { Intermediário }\end{array}$ & $\begin{array}{l}\text { CPRE } \\
9,0 \%\end{array}$ \\
\hline
\end{tabular}




\begin{tabular}{|c|c|c|c|c|c|c|}
\hline & & & & $19,4 \%$ & $23,9 \%$ & \\
\hline \multirow{2}{*}{$\begin{array}{c}\text { Feminino } \\
3,0 \%\end{array}$} & $\begin{array}{c}\text { Divorciado } \\
3,0 \%\end{array}$ & \multirow{2}{*}{$\begin{array}{l}\text { Não } \\
32,8 \%\end{array}$} & $\begin{array}{c}\text { Pós-graduação Lato } \\
\text { Sensu } \\
32,8 \%\end{array}$ & $\begin{array}{l}\text { Interior } \\
25,4 \%\end{array}$ & $\begin{array}{l}\text { Of. Subalterno } \\
55,2 \%\end{array}$ & $\begin{array}{l}\text { CPM } \\
29,9 \%\end{array}$ \\
\hline & $\begin{array}{c}\text { União Estável } \\
9,0 \%\end{array}$ & & $\begin{array}{c}\text { Mestrado } \\
2,2 \%\end{array}$ & & & $\begin{array}{c}\text { Outra Unidade } \\
\text { administrativa } \\
40,3 \%\end{array}$ \\
\hline
\end{tabular}

Fonte: Elaborado pelo autor a partir dos dados da pesquisa (2017)

Dos participantes, há uma supremacia do sexo masculino, com apenas $3 \%$ das respostas feitas por pessoas do sexo feminino. Números como esses são corroborados em Silva (2006), ao mostrar que, atualmente, no Brasil, ainda há uma pequena porcentagem de mulheres nos quartéis, portanto, a instituição militar é vista como um espaço masculino. No tocante ao estado civil, encontra-se a predominância de indivíduos casados, com pouca variação entre as demais opções, tendo os divorciados com o menor percentual. A maioria possui filhos.

Quanto ao grau de escolaridade, não foram marcadas as opções de ensino médio completo, sendo esse o requisito mínimo para ingresso nas fileiras da corporação, tampouco, Doutorado. Há uma maioria com ensino superior completo, com $62,7 \%$, vindo logo atrás os membros com Pósgraduação Lato Sensu, com 32,8\%. Superior incompleto e Mestrado alcançaram pouca significância percentual. A capital do estado é a residência da maioria, com $55,2 \%$ das respostas, vindo o interior em seguida, com a região metropolitana por último.

Em relação ao Posto/Patente, há os Oficiais Subalternos como maior parte dos colaboradores. Oficiais Intermediários e Oficiais Superiores vêm, respectivamente, na sequência. Esse dado é explicado pela proporção de Tenentes existentes nos quadros de Oficiais da Instituição policial militar estadual, demonstrados no Mapa de Oficiais referente ao 1o trimestre de 2017, documento com origem na Diretoria de Pessoal da PM. Com um universo de 485 Oficiais no geral, os subalternos aparecem em número de 175, acompanhado por 154 intermediários e 156 superiores. Os grandes comandos tiveram maioria em sua somatória, porém, os Oficiais de unidades administrativas superaram em valores relativos. O CPM vem em $2 \circ$ lugar, acompanhado do CPI e, logo após, o CPRE. A seguir a Tabela 2 demonstra a proximidade do Oficial com a Lei Seca, no seu respectivo labor.

Tabela 2. Experiência dos Entrevistados com o Cotidiano da Lei Seca

\begin{tabular}{c|c|l|l|l}
\hline OPINIÃO & $\begin{array}{l}\text { 8. Você já foi } \\
\text { parado na blitz da } \\
\text { Lei Seca? }\end{array}$ & $\begin{array}{l}\text { 9. Você conhece } \\
\text { alguém que deixou } \\
\text { de dirigir após } \\
\text { consumir bebida } \\
\text { alcoólica em virtude } \\
\text { da Lei Seca? }\end{array}$ & $\begin{array}{l}\text { 10. Você conhece } \\
\text { alguém que, mesmo } \\
\text { com a Lei Seca, } \\
\text { continua dirigindo } \\
\text { após ter ingerido } \\
\text { bebida alcoólica? }\end{array}$ & $\begin{array}{l}\text { 19. Você conhece alguém } \\
\text { que já foi multado por não } \\
\text { soprar o “bafômetro" e, } \\
\text { mesmo assim, continua } \\
\text { dirigindo após consumir } \\
\text { bebida alcoólica? }\end{array}$ \\
\hline SIM & $35,8 \%$ & $70,1 \%$ & $97,0 \%$ & $61,2 \%$ \\
NÃO & $64,2 \%$ & $29,9 \%$ & $3,0 \%$ & $38,8 \%$ \\
\hline
\end{tabular}

Fonte: Elaborado pelo autor a partir dos dados da pesquisa (2017) 
$\mathrm{Na}$ tabela 2, aparecem questionamentos sobre a possível experiência pessoal dos colaboradores com temas relacionados à Lei Seca. Quando indagados se já haviam sido parados em blitz, apenas 35,8\% indicou ter sido parado, pelo menos uma vez, em alguma blitz realizada no estado. Esse fato pode ser explicado pela concentração das ações repressivo-preventivas da lei na área da capital, tendo menor atuação nas regiões metropolitanas e do interior dessa unidade da federação.

Um dos objetivos da Lei Seca é coibir o consumo de álcool pelos condutores de veículos, com isso quando questionado se conhecia alguém que deixou de dirigir após consumir bebida alcoólica em virtude da Lei Seca, tem-se uma média de 70,1\% de respostas positivas no sentido de conhecer alguém que mudou de comportamento. Porém, em contraponto ao item anterior, $97 \%$ das respostas confirmaram que conhecia alguém que, mesmo com a Lei Seca, continua dirigindo após ter ingerido bebida alcoólica.

Esses dados estão em consonância com os resultados obtidos na Pesquisa Nacional de Saúde (2015) apresentados na introdução deste artigo, em que $23,4 \%$ dos motoristas admite conduzir veículos automotores, mesmo após consumo de álcool, o que reforça a necessidade na manutenção de ações de reforço à Lei Seca.

Soprar o "bafômetro" é facultado aos condutores abordados pelos agentes da blitz da Lei Seca. Dessa forma, a não aceitação do pedido do agente da lei, configura infração, o que gera uma multa pesada ( $R \$ 2.934,00$ ) e outras sanções administrativas. A questão 11 mostra que 61,2\% respondeu que conhece quem permaneça com a prática de beber e dirigir, mesmo já tendo sofrido sanções como as citadas acima. Isso mostra uma resistência à mudança pretendida pela lei por parte da população, levando a crer que a multa pode não ser um meio tão eficaz de levar o cidadão a novas posturas.

Sobre os efeitos gerais da Lei Seca, são apresentadas as próximas tabelas com os dados da pesquisa de campo.

Tabela 3. Entendimento Sobre os Efeitos Gerais da Lei Seca

\begin{tabular}{|c|c|c|c|c|}
\hline OPINIÃO & $\begin{array}{l}\text { 11. A Lei seca é uma } \\
\text { política importante para o } \\
\text { contexto social, pois inibe } \\
\text { completamente o } \\
\text { consumo de bebidas } \\
\text { alcoólicas por parte dos } \\
\text { motoristas. }\end{array}$ & $\begin{array}{l}\text { 12. A população tem } \\
\text { pleno conhecimento } \\
\text { de todas as } \\
\text { consequências ao } \\
\text { desrespeitar a Lei Seca. }\end{array}$ & $\begin{array}{l}\text { 13. A Lei Seca } \\
\text { promove } \\
\text { resultados muito } \\
\text { positivos no } \\
\text { tocante à } \\
\text { diminuição dos } \\
\text { acidentes. }\end{array}$ & $\begin{array}{l}\text { 14. A Lei Seca } \\
\text { promove a } \\
\text { diminuição no } \\
\text { consumo } \\
\text { abusivo de } \\
\text { álcool. }\end{array}$ \\
\hline $\begin{array}{c}\text { Discordo } \\
\text { Totalmente }\end{array}$ & $4,4 \%$ & $6,0 \%$ & --- & $10,4 \%$ \\
\hline $\begin{array}{c}\text { Discordo } \\
\text { Parcialmente }\end{array}$ & $11,9 \%$ & $17,9 \%$ & $3,0 \%$ & $11,9 \%$ \\
\hline $\begin{array}{l}\text { Não Concordo, } \\
\text { Nem Discordo }\end{array}$ & $1,7 \%$ & $1,4 \%$ & $3,0 \%$ & $4,6 \%$ \\
\hline $\begin{array}{c}\text { Concordo } \\
\text { Parcialmente }\end{array}$ & $71,6 \%$ & $49,3 \%$ & $37,3 \%$ & $50,7 \%$ \\
\hline $\begin{array}{l}\text { Concordo } \\
\text { Totalmente }\end{array}$ & $10,4 \%$ & $25,4 \%$ & $56,7 \%$ & $22,4 \%$ \\
\hline
\end{tabular}

Fonte: Elaborado pelo autor a partir dos dados da pesquisa (2017) 
Ao ser questionado sobre o fato da Lei Seca ser uma política importante para o contexto social, pois inibe completamente o consumo de bebidas alcoólicas por parte dos motoristas, $82 \%$ concordam totalmente ou parcialmente, demonstrando a visão de que já existe uma posição na mente das pessoas sobre os deveres sociais ou de cidadania que a lei busca incutir e difundir.

Questionados sobre a população ter pleno conhecimento de todas as consequências ao desrespeitar a Lei Seca, 74,7\% concordam totalmente ou parcialmente. Nesse diapasão, com a premissa descrita no art. 3 da Lei de introdução ao Código Civil, "ninguém se escusa de cumprir a lei, alegando que não a conhece", a população tem plena ciência dos resultados que a desobediência, de qualquer espécie, à norma pode acarretar.

Há quase unanimidade dos investigados (94\%) ao concordar que, de alguma forma, a Lei Seca promove resultados muito positivos no tocante à diminuição de acidentes. Acompanhando esse raciocínio, não houve qualquer resposta envolvendo a opção de "Discordo totalmente", levando a crer que é consenso o entendimento sobre a positividade da política quanto à redução de acidentes. Dados da Polícia Rodoviária Federal sobre mortes provocadas em rodovias federais refletem essa realidade: em 2012, houve 8.663 vítimas fatais, número que caiu para 6.859 em 2015 - uma diminuição de $20 \%$ de óbitos, mesmo com um aumento de $20 \%$ na frota de automóveis no país nesse mesmo período (de 76,1 para 91,1 milhões). (Craide, 2016).

A questão 14 obteve a soma de 73,1\% das variáveis "Concordo totalmente" e "Concordo Parcialmente", quando o assunto foi a promoção da diminuição do consumo abusivo de álcool. Esse dado reflete uma avaliação positiva da Lei Seca como instrumento de promoção na diminuição do consumo do álcool, mesmo sem estar necessariamente ligado ao trânsito.

Dados da Pesquisa Nacional de Saúde do Ministério da Saúde, 13,7\% dos respondentes consumiu álcool em grandes quantidades no último mês, o que corresponde a quatro ou mais doses para mulheres ou cinco ou mais doses para homens em uma única ocasião; se computados somente os homens, esse número chega a 21,6\% (Ibge, 2015), o que pode representar uma contribuição não apenas nos acidentes de trânsito quanto em outros problemas públicos não relacionados com o objeto desta pesquisa como violência contra a mulher, desordem, etc.

A tabela 4 apresenta os efeitos gerais da Lei Seca na percepção dos colaboradores da Lei.

Tabela 4. Entendimento Sobre os Efeitos Gerais da Lei Seca

\begin{tabular}{c|c|l|l|l}
\hline OPINIÃo & $\begin{array}{l}\text { 15. A segurança que as } \\
\text { operaços da blitz da Lei } \\
\text { Seca proporciona é } \\
\text { extremamente relevante, } \\
\text { afinal, a máxima dos } \\
\text { operadores da lei é a } \\
\text { educação e a cidadania. }\end{array}$ & $\begin{array}{l}\text { 16. A Lei Seca } \\
\text { promove mudança } \\
\text { comportamental dos } \\
\text { motoristas, os quais } \\
\text { não dirigem após a } \\
\text { ingestão de bebidas } \\
\text { alcoólicas. }\end{array}$ & $\begin{array}{l}\text { 17. A população } \\
\text { conhece com } \\
\text { detalhes os } \\
\text { limites de } \\
\text { consumo de } \\
\text { álcool } \\
\text { estabelecidos pela } \\
\text { legislação. }\end{array}$ & $\begin{array}{l}\text { 18. A não } \\
\text { obrigatoriedade } \\
\text { de soprar o } \\
\text { "bafômetro" } \\
\text { torna a Lei Seca } \\
\text { ineficiente. }\end{array}$ \\
\hline $\begin{array}{c}\text { Discordo } \\
\text { Totalmente } \\
\begin{array}{c}\text { Discordo } \\
\text { Parcialmente }\end{array}\end{array} \quad 1,5 \%$ & $6.0 \%$ & $23,9 \%$ & $26,9 \%$ \\
\hline
\end{tabular}




\begin{tabular}{c|cccc}
\hline $\begin{array}{c}\text { Não Concordo, } \\
\text { Nem Discordo }\end{array}$ & $1,5 \%$ & $3,0 \%$ & $4,4 \%$ & $4,4 \%$ \\
\hline $\begin{array}{c}\text { Concordo } \\
\text { Parcialmente }\end{array}$ & $41,8 \%$ & $67,2 \%$ & $41,8 \%$ & $35,8 \%$ \\
\hline $\begin{array}{c}\text { Concordo } \\
\text { Totalmente }\end{array}$ & $40,3 \%$ & $11,9 \%$ & $6,0 \%$ & $7,5 \%$ \\
\hline
\end{tabular}

Fonte: Elaborado pelo autor a partir dos dados da pesquisa (2017)

A questão 15 aborda três fatores distintos, porém, intrinsecamente relacionados à abordagem da Lei Seca: a segurança, a educação e a cidadania. Os dois primeiros fatores são base para o terceiro, como se pode perceber na visão de Silva (2011) quando afirma que a relação entre educação e segurança pública, especialmente no Brasil, na ótica da cidadania e direitos humanos parecem ser muito próximas no papel, mas na prática não se concretiza de maneira eficaz. Nessa perspectiva, $82,1 \%$ dos Oficiais participantes da pesquisa concorda com o teor da afirmativa 15 , corroborando com a citação acima, buscando a construção de um comprometimento entre poder público e sociedade com a finalidade de alcançar a cidadania plena, apesar das dificuldades.

A mudança de comportamento dos condutores de veículos é um dos objetivos da Lei Seca. Na questão 16, 79,1\% dos oficiais colaboradores concordam com a assertiva, porém, verifica-se uma diferença considerável na porcentagem de quem concorda parcialmente para aqueles que concordam totalmente.

Na questão 17, que busca identificar a percepção dos respondentes se a população conhece os detalhes dos limites do consumo de álcool estabelecidos pela legislação, observou-se equilíbrio: $47,8 \%$ dos oficiais concordam e 47,8\% discordam de alguma forma. A diferença encontrada foi na proximidade percentual das variáveis discordantes, ambas com $23,9 \%$, enquanto quem concorda parcialmente corresponde a $41,8 \%$ e, totalmente, $6,0 \%$ das opiniões; a questão ainda apresentou 4,4 de respostas neutras.

Em que pese a própria nomenclatura popular da Política Nacional sobre o Álcool, Lei Seca, ainda há dúvida sobre os percentuais de álcool no organismo. A Lei no 11.705/2008, primeira versão da Lei Seca, estabelece em seu artigo 276 que "qualquer concentração de álcool por litro de sangue sujeita o condutor às penalidades previstas no art. 165 deste Código", quais sejam: perda de sete pontos na carteira (infração gravíssima), multa ( $\mathrm{R} \$ 945,00)$ e suspensão do direito de dirigir por 12 (doze) meses, além de medida administrativa - "retenção do veículo até a apresentação de condutor habilitado e recolhimento do documento de habilitação" (Brasil, 2008).

A nova Lei Seca (12.760/2012) aumentou a multa e passou a considerar a recusa em submeter-se aos testes como uma infração sujeito às penalidades dos art. 165 . No entanto, caso o condutor apresente valores iguais a $0,06 \mathrm{ml}$ de álcool por litro de sangue ou 0,3 $\mathrm{mg}$ de álcool por litro de ar alveolar deverá, não somente pagar a multa e ter a carteira de habilitação suspensa por 12 meses, como pode ser levado à prisão e liberado mediante fiança, segundo o artigo 322 do Código de Processo Civil (CPP).

A Lei, como fora visto anteriormente, permite que o condutor negue-se a soprar o "bafômetro", pois, mesmo tendo ingerido bebida alcoólica, ninguém é obrigado a produzir provas 
contra si, prova essa que seria atestada no aparelho etilômetro (prova documental). Na questão 18 (A não obrigatoriedade de soprar o "bafômetro" torna a Lei Seca ineficiente), verificaram-se respostas com valores próximos aos da questão anterior, variando pouco. As opiniões - de quem discorda totalmente e parcialmente - aumentaram, somando $52,3 \%$, enquanto quem concorda somou $43,3 \%$. Continua a análise do entendimento sobre os efeitos gerais da Lei Seca na tabela 5 :

Tabela 5. Entendimento Sobre os Efeitos Gerais da Lei Seca

\begin{tabular}{c|l|l|l|l}
\hline OPINIÃo & $\begin{array}{l}\text { 20. A multa aplicada } \\
\text { aos motoristas que } \\
\text { se negam a soprar o } \\
\text { “bafômetro” gera } \\
\text { compreensão e inibe } \\
\text { o consumo de } \\
\text { bebidas alcoólicas } \\
\text { pelos condutores. }\end{array}$ & $\begin{array}{l}\text { 21. Se a pena para o } \\
\text { condutor que for } \\
\text { condenado por dirigir } \\
\text { sob a influência de } \\
\text { álcool fosse agravada, } \\
\text { diminuiria o número de } \\
\text { motoristas que dirigem } \\
\text { alcoolizados. }\end{array}$ & $\begin{array}{l}\text { 22. Há redução } \\
\text { significativa de } \\
\text { acidentes em } \\
\text { virtude da } \\
\text { existência da Lei } \\
\text { Seca. }\end{array}$ & $\begin{array}{l}\text { 23. Durante as blitz da } \\
\text { Lei Seca é importante } \\
\text { o acompanhamento } \\
\text { 'in loco' de outros } \\
\text { profissionais como: } \\
\text { psicólogos, policiais } \\
\text { civis e assistentes } \\
\text { sociais. }\end{array}$ \\
\hline $\begin{array}{c}\text { Discordo } \\
\text { Totalmente } \\
\text { Discordo }\end{array}$ \\
$\begin{array}{c}\text { Parcialmente } \\
\text { Não Concordo, } \\
\text { Nem Discordo } \\
\text { Concordo }\end{array}$ & $10,4 \%$ & $19,4 \%$ & $4,5 \%$ & $17,9 \%$ \\
$\begin{array}{c}\text { Parcialmente } \\
\text { Concordo }\end{array}$ & $10,6 \%$ & $6,0 \%$ & $3,0 \%$ & $14,9 \%$ \\
Totalmente
\end{tabular}

Fonte: Elaborado pelo autor a partir dos dados da pesquisa (2017)

Sobre a multa gerada ao condutor negar-se a soprar o bafômetro, que após a reformulação da lei em 2012, dobrou de cinco para dez vezes, passando de $\mathrm{R} \$ 945,00$ para $\mathrm{R} \$ 2.934,70$, a questão 20 afirma que essa punição gera compreensão e inibe o consumo de álcool pelos condutores. Observa-se que $76,1 \%$ concordam em algum grau que isso se aplique à realidade, tendo aproximadamente $21 \%$ das opiniões discordando totalmente ou parcialmente.

A questão 21 trata do agravamento da pena para o condutor flagrado conduzindo veículo sob a influência alcoólica. Atualmente, a pena consiste em detenção, de seis meses a três anos, multa e suspensão ou proibição de dirigir. $71,6 \%$ dos colaboradores opinaram concordando com a afirmativa, levando a conclusão de que penas mais severas podem fazer a lei mais eficaz. Ratificando o entendimento da questão $21,88 \%$ dos oficiais, na questão 22 , concordam que a Lei Seca é eficaz na redução de acidentes, apesar de haver outros objetivos dentro do texto da lei.

Apesar de não ser obrigatória a presença dos profissionais citados na questão $23,61,2 \%$ dos Oficiais concordam que é importante o acompanhamento deles, 'in loco', junto às blitzen. A próxima tabela (Tab.6) apresenta as últimas variáveis investigadas.

Tabela 6. Entendimento dos entrevistados sobre os efeitos gerais da Lei Seca

\begin{tabular}{c|l|l|l}
\hline \multirow{3}{*}{ OPINIÃo } & $\begin{array}{l}\text { 24. Aplicativos de } \\
\text { aparelhos telefônicos } \\
\text { móveis, como Uber, Easy } \\
\text { Taxi e Taxi 99 são, }\end{array}$ & $\begin{array}{l}\text { 25. A tropa empregada } \\
\text { nas blitz da Lei Seca é } \\
\text { qualificada para } \\
\text { promover um bom }\end{array}$ & $\begin{array}{l}\text { 26. Os transtornos decorrentes das } \\
\text { blitz da Lei Seca, como } \\
\text { engarrafamentos, lentidão no } \\
\text { trânsito, demora na verificação no }\end{array}$ \\
\hline
\end{tabular}




\begin{tabular}{c|c|c|c}
\hline & $\begin{array}{l}\text { definitivamente, a } \\
\text { solução para o problema } \\
\text { de consumo de bebida } \\
\text { alcoólica por motoristas. }\end{array}$ & $\begin{array}{l}\text { atendimento ao } \\
\text { cidadão abordado. }\end{array}$ & $\begin{array}{l}\text { nível de alcoolemia e nos } \\
\text { procedimentos junto às autoridades } \\
\text { de polícia judiciária, são fatores que } \\
\text { comprometem e desabonam a } \\
\text { fiscalização. }\end{array}$ \\
\hline $\begin{array}{c}\text { Discordo } \\
\text { Totalmente }\end{array}$ & $22,4 \%$ & $29,9 \%$ \\
$\begin{array}{c}\text { Discordo } \\
\text { Parcialmente }\end{array}$ & $13,4 \%$ & $4,5 \%$ & $25,4 \%$ \\
$\begin{array}{c}\text { Não Concordo, } \\
\text { Nem Discordo }\end{array}$ & $4,5 \%$ & $5,9 \%$ & $5,9 \%$ \\
$\begin{array}{c}\text { Concordo } \\
\text { Parcialmente }\end{array}$ & $44,8 \%$ & $20,9 \%$ & $25,4 \%$ \\
$\begin{array}{c}\text { Concordo } \\
\text { Totalmente }\end{array}$ & $14,9 \%$ & $46,3 \%$ & $13,4 \%$ \\
\hline
\end{tabular}

Fonte: Elaborado pelo autor a partir dos dados da pesquisa (2017)

A questão 24 cita alguns aplicativos de telefone celular móvel (smartphones), como solução para o problema de consumir bebidas alcoólicas e dirigir em seguida, já que facilitam a vida dos usuários com a praticidade e o menor custo do serviço de transporte oferecido. $59,7 \%$ dos consultados concordam total ou parcialmente com a assertiva em tela, já $35,8 \%$ discordam de alguma forma.

Sobre a qualificação da tropa empregada nas blitz da Lei Seca a fim de prestar um bom serviço à sociedade, observou-se na questão 25 que 68,7\% dos Oficiais concordando total ou parcialmente. Dessa forma, mostra-se o entendimento de que os profissionais são bem qualificados e podem gerar uma melhor prestação de serviço. Vê-se nessa mesma questão, na variável "Não Concordo, Nem Discordo", um aumento na porcentagem em relação a essa mesma variável nas questões anteriores, atingindo um patamar de $20,9 \%$. Talvez, a falta de conhecimento ou a não difusão de notícias sobre treinamentos ou capacitações através de publicidade, inerentes ao serviço prestado nas blitz, pode ter contribuído para o aumento do valor dessa variável em relação às demais.

$\mathrm{Na}$ última questão, de número $26,55,3 \%$ discordam total ou parcialmente, que os transtornos gerados pelas blitz são fatores que comprometem e desabonam a fiscalização, enquanto $38,8 \%$ concordam com a assertiva.

\section{CONCLUSÃO}

Através das análises procedidas, conclui-se que os Oficiais da polícia militar estadual, com a formação e capacitação voltadas para a implementação, gestão e controle institucional de políticas de segurança pública, lançaram um olhar crítico sobre três fatores principais da Lei Seca abordados no questionário disponibilizado: social, legal e financeiro.

Lotados e morando nos mais diversos rincões do Estado, foi possível obter ampla gama de realidades vivenciadas pelos colaboradores e que serviram de base para os dados tratados nesta pesquisa. Houve relatos de experiências pessoais e de terceiros, levando ao entendimento de não 
apenas ter uma opinião meramente pessoal, mas com fortes influências da vivência de outras pessoas apontadas pelos oficiais.

Para os respondentes, a Lei Seca é importante para mudar uma realidade cultural de beber e dirigir, apesar de ser necessário outros atores para, em conjunto, usar da sinergia para ampliar a área de abrangência e gerar mais resultados positivos. Apesar de saber das consequências penais e administrativas inerentes à Lei Seca, os dados apontam que ainda há muitos condutores dirigindo após consumir álcool, levando perigo iminente à população que circula nas vias de tráfego. A cidadania, obtida em parte pela segurança pública e pela educação foi abordada nas afirmativas e a maioria dos entrevistados concordou. A população sabe dos rigores da lei, um dos pilares da cidadania, porém, descumpre a normativa legal ao permanecer abusando do consumo de bebidas alcoólicas e dirigindo.

As pesadas multas inibem parte dos condutores, mas há quem resista a beber e conduzir veículos, mesmo com tamanha pena pecuniária imposta. Isso mostra a necessidade do investimento nas ações de fiscalização da Lei Seca, que tem levado a diminuição no número de acidentes sem e com vítimas fatais, mesmo com o aumento da frota de veículos.

Como pesquisas futuras, sugere-se que se avalie sobre a perspectiva do cidadão comum, principal usuário das políticas, e as implicações da política em seu cotidiano e dos que o circundam, como familiares e demais grupos de referência.

\section{REFERÊNCIAS}

ADORNO, Rubens de Camargo Ferreira.(2008). Uso de Álcool e Drogas e Contextos Sociais da Violência, SMAD, Revista Eletrônica Saúde Mental Álcool Drogas, Ribeirão Preto, v.4, n.1, p. 9.

ALA-HARJA, Marjukka; HELGASON, Sirgurdur.(2000). Em direções a melhores práticas de avaliação, Revista do Serviço Público, ano 51, n. 4, out-dez.

BECHELAINE, Cinthia H. de O.; CKAGNAZAROFF, Ivan B. (2014). Por que as avaliações vão para a gaveta? Uma revisão teórica dos fatores relacionados ao uso dos resultados das avaliações de políticas públicas. Contabilidade, Gestão e Governança, v. 17, n. 2, p. 78-93.

BRASIL. (2004). Relatório Final da 12ª Conferência Nacional de Saúde. Brasília, Editora MS.

BRASIL. (1997).Lei no 9.503, de 23 de Setembro de 1997. Institui o Código de Trânsito Brasileiro. Disponível em <http://www.planalto.gov.br/ccivil_03/leis/L9503.htm> Acesso em 15 out.

BRASIL.(2008) Lei no 11.705, de 19 de Junho de 2008. Altera a Lei n 9.503, de 23 de setembro de 1997, que 'institui o Código de Trânsito Brasileiro', e a Lei no 9.294, de 15 de julho de 1996, que dispõe sobre as restrições ao uso e à propaganda de produtos fumígeros, bebidas alcoólicas, medicamentos, terapias e defensivos agrícolas, nos termos do § 4으 do art. 220 da Constituição Federal, para inibir o consumo de bebida alcoólica por condutor de veículo automotor, e dá 
outras providências. Disponível em <http://www.planalto.gov.br/ccivil_03/_Ato20072010/2008/Lei/L11705.htm> Acesso em: 15 out.2017.

BRASIL. (2011). Legislação e políticas públicas sobre drogas no Brasil. Brasília: Ministério da Justiça, Secretaria Nacional de Políticas sobre Drogas.

BRASIL. (2012). Lei no 12.760, de 20 de Dezembro de 2012. Altera a Lei $n^{\circ} 9.503$, de 23 de setembro de 1997, que institui o Código de Trânsito Brasileiro. Disponível em <http://www.planalto.gov.br/ccivil_03/_ato2007-2010/2008/lei/l11705.htm> Acesso em 15 out. 2017.

BRASIL.(2017). Observatório Brasileiro de Informações Sobre Drogas - OBID. Ministério da Justiça. Disponível em: www.obid.senad.gov.br Acesso em: abr.

CARVALHO, Edilson Alves de; ARAÚJO, Paulo César de. (2008). Leituras Cartográficas e interpretações estatísticas I: Geografia, Natal-RN, EDUFRN.

CASTRO, Jorge Abrahão de; OLIVEIRA, Marcio Gimene de. (2014). Políticas Públicas e Desenvolvimento, Avaliação de Políticas Públicas, Porto Alegre, UFRGS-CEGOV.

COSTA, Frederico Lustosa da; CASTANHAR, José Cezar. (2003). Avaliação de programas públicos: desafios conceituais e metodológicos, Revista de Administração Pública, Rio de Janeiro, p. 971976 , set/out.

CRAIDE, SABRINA. (2017). Após 4 anos de tolerância zero na lei seca, motoristas ainda resistem a mudanças. EBC/Agência Brasil, Brasília, 28 abr. 2016. Disponível em <http://agenciabrasil.ebc.com.br/geral/noticia/2016-04/apos-4-anos-de-tolerancia-zero-leiseca-motoristas-ainda-resistem-a-mudar-habitos> Acesso em 12 out.

GIL, Antônio Carlos. (2008). Métodos e técnicas de Pesquisa social, 6. Ed., São Paulo, Atlas.

IBGE. (1993). Normas de apresentação tabular. Fundação Instituto Brasileiro de Geografia e Estatística, 3. Ed., Rio de Janeiro, IBGE.

IBGE. (2015).Pesquisa nacional de saúde 2013: percepção do estado de saúde, estilos de vida e doenças crônicas. Rio de Janeiro: Instituto Brasileiro de Geografia e Estatística.

MALTA, Débora Carvalho et. al. (2014). Consumo de Bebidas Alcoólicas e direção de veículos, balanço da Lei Seca, Brasil 2007 a 2013. Revista de Saúde Pública, São Paulo, vol. 48, n. 4, ago.

NEIROTTI, Nerio.(2012). Evaluation in Latin America: paradigms and practices. In: KUSHNER, Saville; ROTONDO, Emma (Org.). Evaluation voices from Latin America. San Francisco: Jossey-Bass.

PAES-SOUSA, Rômulo. (2014).Políticas sociais e desigualdades no Brasil. Avaliação de Políticas Públicas, Porto Alegre, UFRGS-CEGOV.

PAVIANI, Aldo. (2009). Demandas sociais e ocupação do espaço urbano. O caso de Brasília, DF. Cadernos metrópole 21, p. 75, 1ㅇs. sem. 
RAMOS, Marília Patta; SCHABBACH, Letícia Maria. (2012). O estado da arte da avaliação de políticas públicas: conceituação e exemplos de avaliação no Brasil. Revista de Administração Pública, Rio de Janeiro, set/out.

SILVA, Cristina Rodrigues da. (2006).Gênero, Hierarquia e Forças Armadas: um estudo etnográfico sobre as mulheres nos quartéis. Associação Brasileira de Antropologia, São Carlos - SP.

SILVA, Raimundo Paulino da. (2011). Educação e segurança pública: uma perspectiva de cidadania e direitos humanos. Revista Espaço Acadêmico, n. 125, ano XI.

SILVEIRA, Denise Tolfo; CÓRDOVA, Fernanda Peixoto. (2009). Métodos de Pesquisa, Unidade $2-A$ pesquisa Científica. Porto Alegre, Editora da UFRGS.

SOUZA, Celina. (2006). Políticas Públicas: uma revisão da literatura. Sociologias, Porto Alegre, ano 8, no 16, p. 20-45, jul/dez.

SOUZA, Jacqueline de; KANTORSKY, Luciane Prado. (2007). Embasamento Político das Concepções e Práticas referentes às Drogas no Brasil, SMAD. Revista Eletrônica Saúde Mental Álcool Drogas, Ribeirão Preto, v. 3, n. 1.

TEIXEIRA, Elenaldo Celso. (2002).O papel das políticas publicas no desenvolvimento local e na transformação da realidade.

THOENIG, Jean-Claude. (2000). A avaliação como conhecimento utilizável para reformas de gestão pública. Revista do Serviço Público, ano 51, n. 2, abr-Jun.

TINOCO, Dinah dos Santos; SOUZA, Lincoln Morais de; OLIVEIRA, Alba Barbosa de (2011).Avaliação de Políticas públicas: Modelos Tradicional e pluralista. Revista de Políticas Públicas, São Luís, v. 15, n. 2, jul/dez.

TREVISAN, Andrei Pittol, BELLEN, Hans Michael Van.(2008). Avaliação de Políticas Públicas: Uma revisão teórica de um campo em construção. Revista de Administração Pública, Rio de Janeiro, 42(3):529-50, mai/jun.

ATHEY, Susan; IMBENS.(2017).Guido W. The State of Applied Econometrics: Causality and Policy Evaluation. The Journal of Economic Perspectives, vol. 31, n. 2, pp. 3-32.

DULCl, Otávio S. (2010). Avaliação de Programas Sociais: Desafios e Potenciais na Construção de um Sistema de Informações. Cadernos de Estudos Desenvolvimento Social em Debate, Brasília, n. 13, pp. 221-237;

JACOB, Steve; SPEER, Sandra; FURUBO, Jan-Eric. (2015). The institutionalization of evaluation matters: Updating the international atlas of evaluation 10 years later. Evaluation, vol. 21, n. 1, pp. 6-31.

MAIA, Michelle P. (2017). Políticas Públicas e Educação: uma Avaliação do Programa Universidade para Todos (Prouni) em Natal/RN. Tese (Doutorado em Ciências Sociais), Universidade Federal do Rio Grande do Norte, Natal. 
MICKWITZ, Per. Policy evaluation. In: JORDAN, Andrew (org.). (2013). Environmental Policy in the EU: Actors, Institutions and Processes. London/New York: Routledge.

WEISS, Carol H. (1993). Where politics and evaluation research meet. Evaluation Practice, vol. 14, n.1, pp.93-106.

SCHOENEFELD, Jonas; ANDREW, Jordan. (2017). Governing policy evaluation?. Towards a new typology. Evaluation, vol. 23, n. 274-293. 